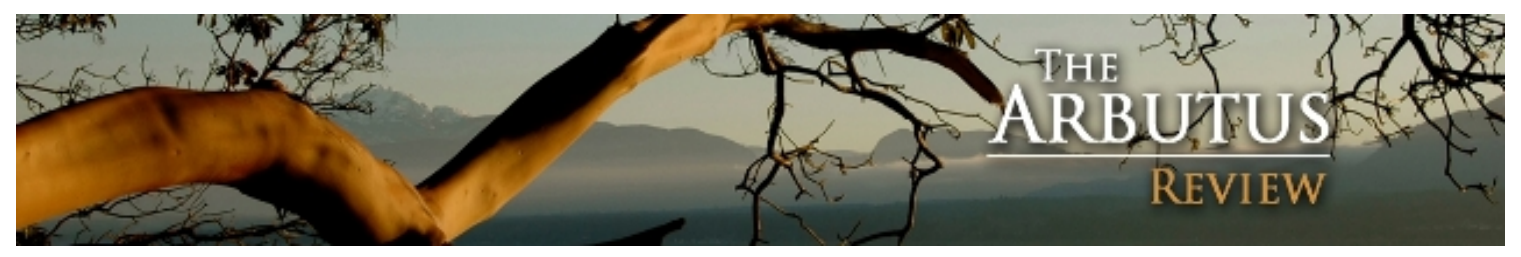

The Arbutus Review is produced by the Division of Learning and Teaching Support and Innovation at the University of Victoria. The Arbutus Review was created to showcase the articles, projects, and installations that result from the Jamie Cassels Undergraduate Research Award (JCURA) program. JCURA was instituted in 2009 as the Undergraduate Research Scholarship program by the then Vice-President Academic and Provost and current past president of the University, Jamie Cassels. It was designed to support and create truly formative research experiences for exceptional undergraduate students. The Division of Learning and Teaching Support and Innovation administers the award nomination process on behalf of the Provost's Office. In addition to submissions that were the result of JCURA research, The Arbutus Review also publishes other exceptional work from students in departments across campus.

We acknowledge with respect the Lekwungen peoples on whose traditional territory the university stands and the Songhees, Esquimalt and WSÁNEĆ peoples whose historical relationships with the land continue to this day.

\title{
Letter from the Managing Editor
}

It is my pleasure to introduce this issue of The Arbutus Review, marking 10 years of publication. Including the six articles in this issue, we have published 94 scholarly articles and creative works by undergraduate authors since our inception in 2010. At the time of writing, authors had cited our students' articles 162 times, with 142 of those citations occurring in the last five years.

This year has been extraordinary due to the unexpected way that the pandemic has changed our lives. In spite of many changes at our university, we are pleased that we have been able to publish two issues this year - a special issue focusing on Indigenous wellness and the second issue I have the pleasure of introducing here. Demands on students this year were great as they transitioned to online learning; nonetheless we received many excellent submissions and the six published here showcase interesting and timely research from undergraduate students at the University of Victoria. All of the articles start as third- or fourth-year course writings, honours papers, or Jamie Cassells Undergraduate Research Award (JCURA) projects and are transformed into publishable articles with the help of supportive instructors, our graduate student peer reviewers, and editors at The Arbutus Review.

I'd like to thank Somayah Abniki, a graduate student in engineering, for her help with LaTeX for this issue.

Also, this issue would not have been possible without the dedication and keen editorial skills of Dr. Madeline Walker (editor). I am grateful to work with Madeline. 


\section{Acknowledgments}

Each of the articles published in this journal is sponsored by an academic mentor (usually a faculty member) at the University of Victoria. For the articles in this issue, we would like to thank the following instructors for their support of an undergraduate research paper.

Dr. Luis Bettio, Division of Medical Sciences

Author: James Choi

Dr. Michael Bodden, Pacific and Asian Studies

Author: Julian Ruszel

Dr. Karen Kobayashi, Department of Sociology

Author: Melina Cortina-Castro

Dr. Olav Krigolson, School of Exercise Science, Physical and Health Education Author: Jillian Toppings

Dr. Helen Kurki , Department of Anthropology

Author: Emma Ronayne

Dr. Margo Matwychuk, Department of Anthropology

Author: Ginny Makovnyka

As well, all submissions are reviewed blind by at least two readers. These readers are graduate students, researchers, instructors, and emeriti from the University of Victoria. We thank them for their very valuable contributions to The Arbutus Review.

Stephanie Arlt

Blythe Bell

Angel Chen

Kate Fairley

Jay Joshi

Georgia King

Mark Shakespear

Ginger Sullivan
Helen von Bucholz

Kimberley Shapkin

David Lark

Jessica Robertson

Juan Sanchez-Arias

Raza Sayer

Katayoun Youssefi 
The Arbutus Review would also like to thank others whose ideas, work and guidance have contributed to the journal.

Laurene Sheilds, Executive Director of the UVic Division of Learning and Teaching Support and Innovation

Inba Kehoe, Copyright Officer and Scholarly Communication Librarian, who provides guidance to the journal and oversees the Online Journal Systems software that allows us to publish online

Madeline Walker, Arbutus Review Editor and typesetter, UVic Centre for Academic Communication Coordinator

Shailoo Bedi, Director (Student Academic Success) of the UVic Division of Learning and Teaching Support and Innovation; Arbutus Review Managing Editor

The opinions expressed in The Arbutus Review are those of the authors and do not necessarily represent those of the Editors of the journal or the University of Victoria. The Arbutus Review is a peer-reviewed journal. While every effort is made by the Editorial Board to ensure that The Arbutus Review contains no inaccurate or misleading citations, opinions, or statements, the information and opinions contained within are the sole responsibility of the authors. Accordingly, the Publisher, the Editorial Board, the Editors, the Advisory Board, and their respective employees and volunteers accept no responsibility or liability for the consequences of any inaccurate or misleading information, opinion or statement.

For more information about the journal, you can contact:

Shailoo Bedi, $\mathrm{PhD}$

Director (Student Academic Success)

Division of Learning and Teaching Support and Innovation

University of Victoria

ltsidirsas@uvic.ca

Madeline Walker, $\mathrm{PhD}$

Coordinator, Centre for Academic Communication

Division of Learning and Teaching Support and Innovation

University of Victoria

cacpc@uvic.ca 